\title{
Human Factors and the Human Domain: Exploring Aspects of Human Geography and Human Terrain in a Military Context
}

\author{
Alex Stedmon ${ }^{1}$, Brendan Ryan ${ }^{2}$, Pat Fryer ${ }^{3}$, Anneley McMillan ${ }^{3}$, \\ Nick Sutherland $^{3}$, and Alyson Langley ${ }^{2}$ \\ ${ }^{1}$ Cultural Communications and Computing Research Institute (C3RI), \\ Sheffield Hallam University, UK \\ a.stedmon@shu.ac.uk \\ ${ }^{2}$ Human Factors Research Group, The University of Nottingham, UK \\ \{brendan.ryan, alyson. langley\} @nottingham.ac.uk \\ ${ }^{3}$ Helyx SIS Ltd, UK \\ \{p.fryer, a.momillan, n. sutherland\}@helyx.co.uk
}

\begin{abstract}
This paper introduces the concept of the Human Domain within military operations and considers how it has evolved from Cultural Geography into more specific sub-components of Human Geography and Human Terrain. At a high level, Human Geography and Human Terrain map across to strategic and tactical decision-making respectively. However, there is a confusing array of terminology and definitions surrounding these factors. Given this complexity, what might have originally been considered a Human Domain continuum from a strategic level down to a tactical level may be better represented as overlapping constructs on a spectrum of understanding, each with their own approaches to data capture and analysis.
\end{abstract}

Keywords: Human Domain, Data Models, Visualisation, Human Factors.

\section{Introduction}

Military operations are shaped by the characteristics of the environment in which they occur. Consequently, the scale, tempo, and complexity of military endeavours are linked to the physical and cultural landscapes of the regions in which they are conducted [1]. Globalisation and the influence of mainstream and social media within civilian society now combine to bring modern warfare, military manoeuvres, and operations other than war (OOW) into people's homes on a daily basis. In recent uprisings such as Arab Spring 2011 new communication technologies and social media were considered critical in coordinating the actions of the local populations [2]. In some ways this may be true, and military events at a tactical level now have the potential to shape public opinion. However, media usage and its impact on local populations, requires both access to the technology and a degree of literacy [3]. This highlights the need to understand underlying socio-demographic factors that are 
essential in planning military interventions. Knowledge of the local area has a profound effect on military strategy as decision-makers seek to influence perceptions, understand sentiment and manage expectations amongst local populations. At the same time a sophisticated and increasingly media-aware and media-enabled enemy will try to exploit public opinion in order to destabilise and alienate populations from the ideals of their own governments and military forces. Understanding the population amongst whom the military must operate, and more specifically their culture, religion, perceptions and expectations, is now so important that it permeates through every aspect of military decision-making and military doctrine.

A former commander of coalition forces in Afghanistan highlighted the importance of understanding the local population with reference to concepts of Human Geography and the Human Terrain in relation to conducting counter insurgency (COIN) operations. Specific areas of difficulty are considered to be:

- the creation of location-specific, geo-social models and patterns of life that reflect spatio-temporal social, cultural, economic, political, religious, ethnic and other dynamic factors;

- the ability to assess local norms and detect deviations through modelling human behaviour and understand common patterns of life;

- understanding and capturing the effects of scale (e.g. nation, province, city, neighbourhood, sect, tribe, individual) and relating these to temporal aspects over different timescales;

- visualising motives, intentions, reactions, interactions between local populations and military forces;

- achieving deep levels of understanding to enable insight and provide opportunities to influence and support decision-making.

From these issues, the aim is to be predictive and understand possible trajectories of behaviour and plan for different 'courses of action' (COAs). The concepts of Human Geography and Human Terrain have been encompassed within the Human Domain that is now a critical element of conflict prevention and crisis management. In many ways this concept is still in its infancy although in reality the British military is re-learning lessons from its colonial past as well as the challenges it faced in the more recent troubles in Northern Ireland. Military doctrine is being re-written to take account of these lessons and is now being applied to future conflicts and embedded within information gathering procedures and information analysis structures [4].

With reference to the forward application of military knowledge, the future character of conflict (FCOC) seeks to identify the nature of military activities through to 2029 in order to guide the planning of organisational structures and operational activities. As global dynamics shift, key threats to stability include climate change, demographic trends, globalisation, access to declining energy resources, failed and failing states, and ideology. With these considerations in mind, the Human Domain is central to understanding and decision-making in military activities. 


\section{Terminology and Definitions}

There are a number of technical challenges in understanding the Human Domain, not least in the proliferation of terminology and definitions that surround it and the concepts it encapsulates. Within the academic and military community, terms such as 'Human Geography', 'Human Terrain', 'Human Dimension', 'Cultural Geography', 'Human Dynamics', 'Patterns of Life' and even 'Human Factors' have evolved with very specific meanings and have been used interchangeably within various academic, doctrinal and operational contexts (see: [5]). Furthermore, many of the above terms have more than one meaning that may conflict with definitions for other concepts in other contexts. The landscape is therefore extremely complex and presents a challenge in determining a common understanding based on a lingua franca.

Human Geography is based on analysing the interconnections between people and places, including the spatial and temporal patterns of human activities in the context of the environment. Human Geography reaches from detailed local studies up to global trends. What gives Human Geography its disciplinary identity is its basis in spatial and temporal relationships. There are three primary themes in Human Geography, each taking account of tome and space [6]:

- economic geography - systems of production, exchange and distribution

- political geography - systems of class/group conflict

- social geography - systems of human interaction

In some ways definitions for Human Terrain seem to overlap with that of Human Geography, but focuses more on the characterisation of cultural, anthropological, and ethnographic information about a human population and their interactions within a joint operational area. Other interpretations include the notion of the soldier 'in the system' and this relates well to systems approaches within Human Factors (e.g. joint cognitive systems, socio-technical systems, etc) where people and technology interact beyond traditional and singular 'human-machine interfaces' (see: [7]). In relation to an environment, among which soldiers operate, Human Terrain must consider the impact and influence that a person has in a given system where others are already interacting.

To a certain extent, the proliferation in terminology and associated definitions is due to similar terms developing through different perspectives (for instance a geographical perspective versus an anthropological or social science perspective). Other differences occur due to an academic concept being applied to a military context. In some cases, context specific terminology may increase understanding within a particular domain or discipline as the terminology is related to other specific ideas and concepts. However terminology specialisation might confuse a common understanding between different domains or disciplines. This is particularly important within the context of FCOC, where concepts such as the centrality of influence, dynamic understanding, adaptive approaches and increased partnerships with allies, all require a common understanding in order to work in an agile and efficient manner. 


\section{De-constructing the Human Domain: Human Geography and Human Terrain}

The Human Domain can be understood in terms of higher-level strategic concepts that relate to aspects of Human Geography, down to lower-level tactical concepts that relate to aspects of Human Terrain. In many ways these two factors represent a continuum but given their levels of complexity it may be more accurate to consider them as overlapping constructs on a spectrum of understanding and analysis, each with their own approaches, some of which may be in common (Figure 1).

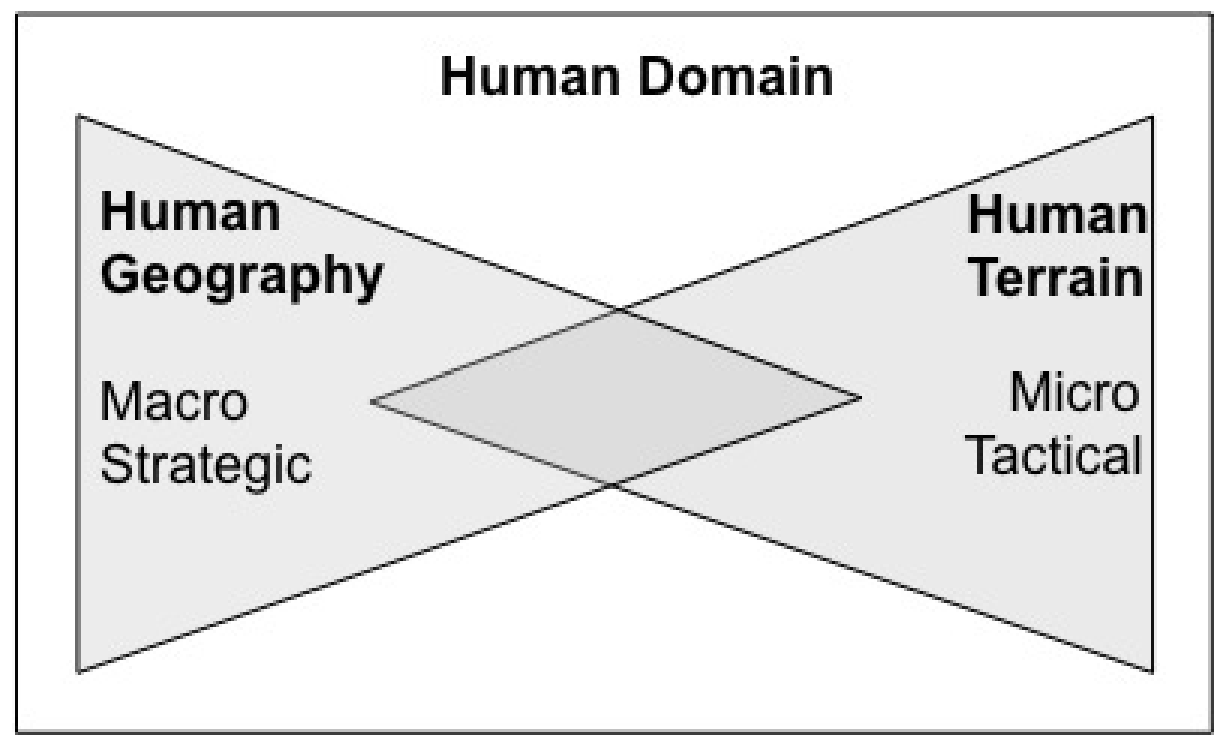

Fig. 1. Overlapping constructs of Human Geography and Human Terrain

\subsection{Human Geography}

Human Geography encapsulates the macro-level detail of a situation and attributes that are unlikely to change in the short term (e.g. physical characteristics of time and space such as buildings, runways, radio masts, etc) and also perhaps stable attributes of a population that may remain largely stable over time (e.g. social identity, ethnicity, etc). These provide a basis for strategic decision-making based on known data that have been gathered and assimilated over a period of time. That said, the period of time over which data are collected is important. Information changes over time in light of new intelligence about a situation. In due course it will be updated when the new data are processed and their credibility confirmed. For example if a bridge has been compromised, intelligence reports will be fed back at a strategic level so that maps and other decision support tools can then be updated. For social factors this may be more challenging. It may be possible to map aspects of general sentiment for a given population (e.g. attitudes are likely to remain static for periods of time) but 
perhaps more difficult to map sentiment for more dynamic factors (e.g. anger at perceived injustices). However, as societies evolve over time, so do the social relations that are:

- established through space (such as the organisation of resource-based activities and environments);

- constrained by space (such as the inertia imposed by the built environment or the limits imposed by natural hazards);

- mediated through space (including the development of ideology and beliefs within geographically confined regions).

In many ways this aspect of Human Geography overlaps with elements of Human Factors. Whilst Human Geography is defined by economies, cultural identities, politics and society, Human Factors focuses on the study of people and human interaction within specific contexts [7]. Many aspects shaping human performance and the way Human Factors considers complex systems are relevant to Human Geography. The temporal dynamics and location-based perspective to Human Geography translates across to fundamental issues in Human Factors such as human performance, workload and situation awareness, where the ability of people to conduct tasks under increased pressure or when dealing with uncertainty are both time and location dependent.

\subsection{Human Terrain}

Human Terrain is defined within Army Tactical Doctrine as the social, political, and economic environment, belief systems and forms of interaction of the people among whom soldiers operate and includes social activities, political frameworks, organisations, people and events [8]. In addition to the identification of such interactions it is critical that they are understood (or interpreted) from the perspective of the local population based on an understanding of what that population wants, needs, and fears in their daily lives [8].

An understanding of the Human Terrain can enable soldiers to more readily distinguish friend from foe [8]. This is critical in operations where soldiers are tasked with operating close to a local population and interacting directly with local forces. Military action, if grounded in an understanding of the Human Terrain, can help build relationships and trust with the local population. This can then be used to foster a sense of safety and security, both of which are foundations for future opportunities and development [8]. In addition, an increase in Human Terrain understanding can also be used to ascertain points of influence, leverages and vulnerabilities within the local population [8]. These can then be avoided when planning operational objectives, all of which should ensure a balance between the officially conveyed command intent and the perceived intent that the local population might derive from the behaviours they observe [8]. In this way, Human Terrain encompasses planning and decision-making in a dynamic environment (relevant to some of the other complex systems/environments in which Human Factors operates).

At a tactical level, Human Terrain reflects the dynamic aspects of time and space (and underlying issues of uncertainty and trust in changing datasets). Human Terrain 
reflects the detail of a situation experienced at an individual or group level as events unfold in real time. Information is processed based on assumptions about the data available (and perhaps referenced back to known Human Geography analysis). At a simple level, whilst the location of a population might remain stable over a period of time, it may well be transient within its boundaries (due to natural disasters, civil unrest, etc). Mass migration is a major issue in conflict when populations shift and need to be relocated/re-housed until they move back again and then resettle in often war-torn areas. At a tactical level, a radio mast may appear on the terrain when it previously was not there and therefore represents a dynamic attribute that may eventually become part of the Human Geography dataset if it remains in place and is authenticated. From a Human Terrain perspective not only is the radio mast present as a physical attribute in the landscape, but it also has a range of transmission (given the local topography and prevailing atmospheric and weather conditions). From the Human Domain perspective more subtle questions may be asked about what is being transmitted and what kind of influence does a particular message have over the local population, given the prevailing dynamics of a situation.

\section{Re-constructing the Human Domain}

From a military perspective, the Human Domain has evolved from aspects of Cultural Geography and involves the military examination of human components within an operational environment, including an integrated picture of the cultural landscape [1]. The result is an appraisal of a region's population, cultural groups, cultural institutions, settlement patterns, land use, economies, transportation and communication networks, and military capabilities [1].

The development of the Human Domain from Cultural Geography provides a basis for exploring aspects of Human Geography and Human Terrain. There is a clear emphasis on socio-cultural factors but linked to this are underlying economic and political factors. One example from a recent military workshop was that in building a new road to support military logistics, a lucrative contract awarded to a local company could have serious consequences if that contractor then develops local political power through being able to buy or bribe support from the local militia. A further example is that in situations where access to water is controlled through canals or sluice gates, different local actors can influence others and exercise power by their control of the waterways. Whilst these situations might be predictable if the right information is gathered and analysed, other situations might be more of a challenge. If a military unit 'promises' to support the local community (perhaps by refurbishing some premises, helping to repair a bridge, etc) but the verbal contract is lost between different rotations of military personnel, then the local community may be reluctant to trust or believe in new promises.

As the Human Domain incorporates the relationships between people and their natural and cultural environments, this relates well to fundamental aspects of Human Factors. There is also a focus on developing and preparing soldiers for specific tasks and this has similarities in training and cultural change within conventional organisations and understanding complex socio-technical systems from a Human Factors 
perspective. A key output is an enduring understanding (that evolves and matures) that is essential in briefing the rotations of military units through an area/region and providing immediate context for them when they arrive in an area.

\section{$5 \quad$ Human Domain Methods and Interpretation}

In a broad sense the Human Domain focuses on observed distributions and analytical explanations that explore social, economic, cultural, political, and demographic dimensions of human existence [9]. However, the Human Domain also includes temporal aspects and location-based perspectives to understand system dynamics.

Whilst there is nearly always data available, all too often the challenge becomes one of identifying the relevant data for a given situation [10]. As a consequence, there is often not enough 'good' data that is reliable and relevant, and what there is, is often incomplete, obsolete, inaccurate, and difficult to validate [10]. What emerges is a lack of detail that reflect spatio-temporal social, cultural, economic, political, religious, ethnic and other dynamic factors. Embedded within these are potential anomalies that could indicate areas of interest and so clearer methods are needed to capture, analyse, understand and ultimately visualise this information and link it to effects of scale and time, and map the motivations, intentions, reactions and interactions that will then provide both strategic and tactical insights for decision-making.

As a result, the collection and analysis of Human Domain data involves quantitative approaches (e.g. population numbers, demographic ratios, etc) and qualitative approaches (e.g. in-depth interviews, observations, ethnographic approaches, etc). Human Factors shares a number of these methods. From a methodological perspective the Human Factors community can help with eliciting information and interpreting the Human Domain. This is a vital contribution that Human Factors can offer and support the military who may not perhaps be used to questioning and collecting information from a civilian population. However, the manner in which such knowledge is produced, and what it means, is dependent on wider political, institutional, and cultural circumstances from where it came, and also on the perspective of the observer or interpreter who collected it [9]. In order to achieve this, it is useful to consider how information might be assimilated into information systems via data models and how that information might then be visualised in a way that is usable and fit for purpose.

\subsection{Information and Data Models}

In order to assimilate, classify and structure Human Domain data, the use of information and data models has been advocated. Building on political, economic and social constructs of geography (as mentioned earlier) these models can range from conceptual data management frameworks, such as the PMESII/ASCOPE frameworks to comprehensive military models such as the GEOINT Structure Implementation Profile (GSIP) designed to capture different levels of detail across the Human Domain. 
PMESII sets out to develop a holistic understanding of Political, Military, Economic, Social, Information, and Infrastructure entities and is aligned to Human, Social, Cultural and Behavourial (HSCB) approaches [5]. ASCOPE builds on the PMESII framework by providing levels of detail based on Area, Structures, Capabilities, Organisations, People, and Events [4]. GSIP defines the methods and structure for specifying and encoding data, and includes specific sub-models that can be extended to cover aspects of Human Geography and Human Terrain data.

With reference to temporal dynamics and a location-based perspective, GSIP will form the basis of the NATO Geospatial Information Framework that aims to specify the content, structure, organisation and exploitation of geospatial information services, delivered over a NATO common geospatial information infrastructure. It will be built on a common content model that includes a feature content dictionary, feature catalogue and data model. Although these models have great capacity to structure data collection, and establish linkages and hierarchies of data, the use of these models also provides their own challenges.

One of the main challenges with the use of data models is that they are currently content-impoverished. This tends to be because Human Domain data does not yet have standard semantics or formats. The development of data standards through the creation of dictionaries, logical models, ontologies, application schemas, feature catalogs and encodings is therefore imperative work to support the population of these data models.

A further challenge is in the analysis of data at the right 'level of detail' for different users. This also means that the analysis must be done in a way that supports military collaboration with non-military agencies who may not be familiar with military concepts. Different levels of detail allow for a common framework of understanding within the Human Domain, from high-level strategic Human Geography detail (e.g. the cultural/social perspective) down to lower-level tactical Human Terrain detail (e.g. the individual perspective).

\subsection{Visualisation}

Once Human Domain data are collected and analysed, further challenges are faced in visualising the results. Traditional challenges are faced when dealing with Human Geography data in terms of representing the accuracy and precision of the data, generalising big data into products at smaller scales, dealing with data gaps, and displaying temporally dynamic data embedded within the Human Terrain. Further challenges are faced when attempting to visualise novel data (e.g. social media data) and representing uncertainty. Visualising sentiment and behaviour is likely to bring its own challenges, particularly if the data provenance is unknown. The solution is likely to be flexible, adaptable, potentially nested frameworks and methodologies that can deal with a range of data types in as consistent manner as possible. It is perhaps in this area that Human Factors can draw from established work in the discipline.

Within Human Factors, a number of topics are relevant to visualising Human Domain data: the interaction of people within systems, including methodologies 
for studying interactions; participatory approaches for user needs and knowledge elicitation; representing uncertainty within user interfaces and visualisations; trust (building trust and relationships) and transparency; planning and decision making in complex, dynamic systems (including systems based approaches); ethnographic and cultural assessment; and aspects of simulation and training.

Returning to the example of the radio mast, if such a feature is observed at the tactical level (e.g. a pilot spots it on a fly-by) but it is not then incorporated at a strategic level into databases or products (e.g. maps), levels of mistrust can result. This can undermine user confidence in existing products (e.g. reliability of the data) based on an assumption that other data may be left out if it has not been authenticated. The time it might take to verify the data also influences the temporal aspect of the Human Domain. If there is a delay in validating data sources portrayed on a map, it may be important to relate this to the user so they know which data may be less certain than others.

\section{Distinctions in Human Geography and Human Terrain}

Any localised military geographical analysis represents a partially processed snapshot of the operational environment at a specific point in time [1]. Earlier military geographical analyses must be revisited and continually updated in order to account for the changing and enduring attitudes and perceptions of a local population, any humanitarian efforts to help the country, and the continuing political, economic, and cultural influences from outside sources [1]. As experience has shown in countries such as Germany and Japan, and more recently in Bosnia and Kosovo, in the aftermath of war sustained peace can be achieved only through effective stability-and-support operations and long-term political and economic commitment [1]. This is a major issue as military objectives such as reconstruction often requires collaboration with Non Government Organisations (NGOs) and international bodies such as the United Nations and World Bank. In order for these activities to be effective and efficient, the data collected and the understanding gained should be sharable with other non-military players. A tactical understanding should be incorporated into all aspects of the planning process and intelligence collection process from: the identification of baseline and comparative data; pre-planning information gathering; to the development of the intelligence and potential effects; through to the understanding of COAs and decisions on control measures [8]. However, the appropriate level of detail is important. For example, an overlay of tribal locations for a particular area of interest may obscure particular dynamics of the environment that can impact on specific COAs and influence opportunities. Furthermore, from the Human Domain perspective, the boundaries of one tribal grouping may not meet the boundaries of another (e.g. tribes will fall across many political and administrative boundaries) making it difficult to collect all the information required to understand the tribe. Thus, integration should ideally be complementary to other forms of intelligence and not be treated as an additional component that can be dealt with in isolation [8]. 


\section{Conclusion}

Being aware of the Human Domain and its impact on operations is a fundamental requirement for planning and conducting military activities: the Human Domain is important to the military perspective. Furthermore, the Human Domain underpins a highly dynamic situation where different components may interact, often creating or at least adding to already difficult circumstances within which military units must function [1]. By creating a better understanding of Human Geography (e.g. the context and the arena in which activities take place) and Human Terrain (the importance of combining different user perspectives) there is a clear opportunity to draw from the knowledge-base and methodological toolbox of Human Factors.

Acknowledgement. This work has been supported and developed through the Advanced Geospatial information and Intelligence Services (AGIS) research project (MOD Contract No: DSTLX-1000063699).

\section{References}

1. Palka, E.J., Galgano, F.A., Corson, M.W.: Operation Iraqi freedom: A military geographical perspective. Geographical Review 95(3), 373-399 (2005)

2. Campbell, D.G.: Egypt Unshackled: Using social media to @\#:) the System. Cambria Books, Amherst (2011)

3. Pfeffer, J., Carley, K.M.: Social networks, social media, social change. In: Proceedings of 4th International Conference on Applied Human Factors and Ergonomics (AHFE 2012), San Francisco, July 21-25 (2012)

4. Hartley III, D.S., Lacy, L.: Creating the foundations for modeling irregular warfare. In: Proceedings of 4th International Conference on Applied Human Factors and Ergonomics (AHFE 2012), San Francisco, July 21-25 (2012)

5. McCloskey, M.J., Behymer, K.J.: Methods for capturing cultural lessons learned and training cross-cultural skills. In: Proceedings of 4th International Conference on Applied Human Factors and Ergonomics (AHFE 2012), San Francisco, July 21-25 (2012)

6. Dear, M.: The postmodern challenge: Reconstructing human geography. Transactions of the Institute of British Geographers, New Series 13(3), 262-274 (1988)

7. Hollnagel, E., Woods, D.D.: Joint Cognitive Systems: Foundations of Cognitive Systems Engineering. CRC Press, Boca Raton (2005)

8. de Vries, A.M.: Analysis for the future of Afghanistan. The human terrain of counterinsurgency operations: Developing the military mindset and social science support. DSTL on behalf of the Controller of HMSO (2010)

9. Gibson, C.: Human geography. In: Kitchin, R., Thrift, N. (eds.) International Encyclopaedia of Human Geography, vol. 5, pp. 218-231. Oxford, Elsevier (2009)

10. Moore, R.A., Stevens, C.M., Oonk, H.M., Averett, M.G.: Operational user requirements and example use cases for Human Social Culture Behavior (HSCB) technologies. In: Proceedings of 4th International Conference on Applied Human Factors and Ergonomics (AHFE 2012), San Francisco, July 21-25 (2012) 